\title{
MRA Versus DSA for Follow-Up of Coiled Intracranial Aneurysms: A Meta-Analysis
}

\author{
M.J. van Amerongen, H.D. Boogaarts, J. de Vries, A.L.M. Verbeek, F.J.A. Meijer, M. Prokop, and R.H.M.A. Bartels
}

\begin{abstract}
SUMMARY: MR angiography is proposed as a safer and less expensive alternative to the reference standard, DSA, in the follow-up of intracranial aneurysms treated with endovascular coil occlusion. We performed a systematic review and meta-analysis to evaluate the accuracy of TOF-MRA and contrast-enhanced MRA in detecting residual flow in the follow-up of coiled intracranial aneurysms. Literature was reviewed through the PubMed, Cochrane, and EMBASE data bases. In comparison with DSA, the sensitivity of TOF-MRA was $86 \%$ (95\% $\mathrm{Cl}: 82-89 \%)$, with a specificity of $84 \%(95 \% \mathrm{Cl}: 81-88 \%)$, for the detection of any recurrent flow. For contrast-enhanced MRA, the sensitivity and specificity were $86 \%$ (95\% Cl: 82-89\%) and $89 \%$ (95\% Cl: 85-92\%), respectively. Both TOF-MRA and contrast-enhanced MRA are shown to be highly accurate for detection of any recanalization in intracranial aneurysms treated with endovascular coil occlusion.
\end{abstract}

ABBREVIATIONS: $C E=$ contrast-enhanced; GRADE = grades of recommendation, assessment, development, and evaluation; SROC $=$ summary receiver operating characteristic

$\mathbf{T}$ he prevalence of unruptured intracranial aneurysms in the world population is approximately $2-3 \% .^{1,2}$ The current standard treatment to eliminate the risk of (re)bleeding is exclusion of the aneurysm from the intracranial circulation by use of endovascular detachable coil occlusion. ${ }^{3}$ However, recurrences occur in approximately $20 \%$ of treated patients, leading to a need for retreatment in approximately $9 \%$ of all cases. ${ }^{4}$

DSA is the reference standard for evaluating aneurysms after coiling. However, this technique exposes patients to risks such as cerebral thromboembolism, contrast nephrotoxicity, and ionizing radiation. The transient neurologic complication rate after DSA has been reported to be in the range of $0.34-1.3 \%$, with a risk for permanent neurologic complications of $0.5 \%$. This risk accumulates because repeated follow-ups are necessary. ${ }^{5-7}$

MRA can be used for follow-up of coiled intracranial aneurysms, with TOF and contrast-enhanced (CE) MRA being the most commonly used techniques currently available. MRA eliminates the risks of cerebral thromboembolism and ionizing radiation. There is, however, a continuing debate about which of these

From the Departments of Neurosurgery (M.J.v.A., H.D.B., J.d.V., R.H.M.A.B.), Epidemiology and Biostatistics (A.L.M.V.), and Radiology/Neuroradiology (F.J.A.M., M.P.), Radboud University Nijmegen Medical Centre, Nijmegen, The Netherlands.

Please address correspondence to Hieronymus D. Boogaarts, MD, Department of Neurosurgery, Radboud University Nijmegen Medical Centre, Reinier Postlaan 4 PO Box 9101, 6500 HB, Nijmegen, The Netherlands; e-mail: h.boogaarts@ nch.umcn.nl

- Indicates open access to non-subscribers at www.ajnr.org

三 Indicates article with supplemental on-line tables

http://dx.doi.org/10.3174/ajnr.A3700

2 MRA techniques is best suited for aneurysm follow-up. The systematic review and meta-analysis performed by Kwee and Kwee $^{8}$ in 2007 compared TOF-MRA and CE-MRA with DSA for follow-up of coiled aneurysms. The analysis revealed a moderate to high diagnostic performance of both MRA techniques. Because of the moderate methodologic quality of the studies available at the time, Kwee and Kwee ${ }^{8}$ could not conclude whether MRA can replace DSA as the standard method of reference. Since then, the number of studies on this subject has more than doubled, and study setup and statistical methodology have substantially improved.

The goal of the current study is to systematically review the medical literature to establish whether TOF-MRA and CE-MRA can now be considered good enough for follow-up of patients with coiled intracranial aneurysms.

\section{MATERIALS AND METHODS \\ Data Sources}

The medical literature comparing MRA and DSA for evaluating intracranial aneurysms after coiling was reviewed through the use of a variety of data bases-PubMed, EMBASE, and the Cochrane Library-and was updated until March 2012 (On-line Table 1).

\section{Study Selection}

After an initial search of the literature by an experienced librarian, duplicate publications were removed. From the pooled list of publications, 2 researchers (M.J.v.A. and H.D.B.) independently reviewed the titles and abstracts of the articles. Studies were ex- 


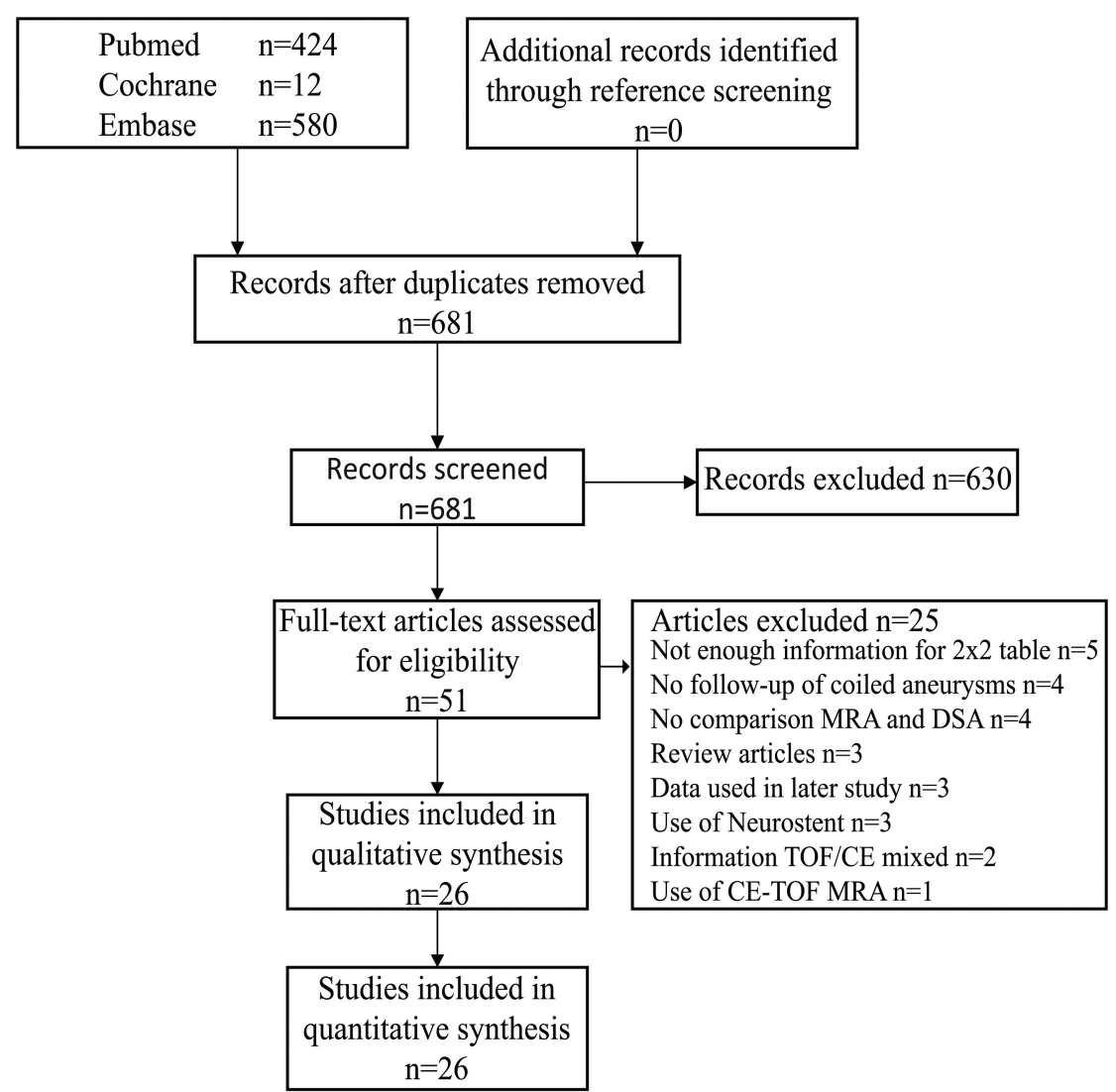

FIG 1. Search results.

cluded if they did not compare MRA with DSA for follow-up of patients with intracranial aneurysms treated with endovascular coil occlusion. Conference abstracts, reviews, editorials, metaanalyses, and animal studies were also excluded. Only articles in English were screened. From the remaining articles, full-text versions were obtained and were independently evaluated by the same researchers (M.J.v.A. and H.D.B.). Studies were eligible for inclusion if they 1) evaluated MRA and DSA for follow-up of patients with intracranial aneurysms treated with endovascular coil occlusion; 2 ) contained data for $2 \times 2$ contingency tables; 3 ) used the Raymond et al classification or other compatible scales to grade recurrent flow in intracranial aneurysms ${ }^{9-11}$; 4) analyzed TOF and CE MRA separately; and 5) provided data that excluded stent-assisted coiling of intracranial aneurysms. If the same data were used in more than 1 article, the most recent version was included. If the 2 researchers disagreed about selection of articles, an independent third reviewer (R.H.M.A.B.) decided the outcome.

\section{Study Quality}

The Grades of Recommendation, Assessment, Development, and Evaluation (GRADE) method was used to assess the methodologic quality of the studies included in this review. ${ }^{12-22}$ The studies were independently assessed by the 2 researchers (M.J.v.A. and H.D.B.) for limitations, indirectness, inconsistency, imprecision, and publication bias. Agreement between the researchers was quantified by use of Cohen $\kappa \cdot{ }^{23}$ In the case of disagreement, a third reviewer (R.H.M.A.B.) made the final decision.

\section{Data Analysis}

The Meta-DiSc software (http://www. hrc.es/investigacion/metadisc_en.htm) and SPSS statistical package (version 19.0.0; IBM, Armonk, New York) were used for statistical analysis. ${ }^{24}$ To evaluate effect size, $2 \times 2$ contingency tables were constructed from the articles comparing MRA and DSA. If the true-positive rate, false-positive rate, true-negative rate, or false-negative rate was zero, a standard correction of 0.5 was added to all of the cells of the contingency table. Pooled sensitivity and specificity with $95 \%$ confidence intervals were constructed. Data about the accuracy of MRA for grading recurrent flow, as defined by Raymond et $\mathrm{al},{ }^{9-11}$ were extracted if available. Classification scales that were compatible with Raymond et al were also utilized, meaning that the findings could be assigned to 1 of the following categories: complete occlusion; residual neck (1-3 mm); and residual aneurysm $(>3 \mathrm{~mm})$. Results were depicted in a Forest plot and a summary receiver operating characteristic (SROC) curve. An SROC curve plots the positive rate against the false-positive rate of a diagnostic test at the different possible cutpoints. Heterogeneity between the studies was examined by use of the $I^{2}$ test. As an indicator of low heterogeneity, a percentage $<40 \%$ was taken. ${ }^{20}$

\section{RESULTS}

\section{Included Studies}

Our search string found 424 studies in PubMed, 12 in Cochrane, and 580 articles in EMBASE (On-line Table 1). A total of 681 studies remained after removal of duplicates. After screening titles and abstracts, 51 articles were deemed fit for full-text evaluation. ${ }^{25-75}$ No new articles were found by screening their references. After evaluation of the full-text versions, 3 articles were excluded because they were review papers. ${ }^{37,51,58}$ Another 5 studies were omitted because they did not provide enough data for the $2 \times 2$ contingency tables. ${ }^{31,45,46,50,53}$ Four further studies were left out because they did not compare MRA with DSA, ${ }^{34,65,72,73}$ and another 4 were not studying intracranial aneurysms treated with endovascular coil occlusion. ${ }^{47,49,57,67}$ Two articles were excluded because information about TOF-MRA and CE-MRA could not be separated. ${ }^{25,71}$ One article was excluded because it used CE-TOFMRA. ${ }^{30}$ Another 3 articles were excluded because their data were used in earlier studies. ${ }^{35,41,44}$ Three studies included patients who had been treated with a secondary Neuroform stent (Stryker Neurovascular, Fremont, California) and were thus omitted (Fig 1). ${ }^{52,54,63}$ This left 26 studies that were eligible for inclusion (Fig 1) (On-line Table 2). ${ }^{26-29,32,33,36,38-40,42,43,48,55,56,59-62,64,66,68-70,74,75}$ Of these articles, 24 researched TOF-MRA ${ }^{26-29,32,33,36,38-40,42,43,48,55,60-62,64,66,68-70,74,75}$ and 14 researched CE-MRA. ${ }^{29,32,36,40,42,56,59,60,62,66,68,70,74,75}$ 
Table 1: Pooled sensitivity and specificity for MRA versus DSA

\begin{tabular}{lccccccccc}
\hline & \multicolumn{4}{c}{ TOF-MRA } & & \multicolumn{3}{c}{ CE-MRA } \\
\cline { 2 - 4 } \cline { 7 - 9 } & Sensitivity & Specificity & Positive LR & Negative LR & & Sensitivity & Specificity & Positive LR & Negative LR \\
\hline Any recanalization & $86 \%(83-89 \%)$ & $86 \%(83-89 \%)$ & $6.3(4.1-9.8)$ & $0.17(0.11-0.25)$ & & $85 \%(81-89 \%)$ & $88 \%(84-91 \%)$ & $6.2(3.6-10.6)$ & $0.16(0.08-0.33)$ \\
Residual neck & $78 \%(71-84 \%)$ & $93 \%(90-95 \%)$ & $9.6(4.5-20.6)$ & $0.29(0.19-0.46)$ & & $56 \%(41-70 \%)$ & $91 \%(84-95 \%)$ & $6.3(1.8-22.5)$ & $0.40(0.15-1.08)$ \\
Residual aneurysm & $83 \%(77-88 \%)$ & $96 \%(94-97 \%)$ & $21.4(10.5-43.7)$ & $0.21(0.13-0.35)$ & & $77 \%(68-85 \%)$ & $90 \%(86-94 \%)$ & $7.5(3.8-14.7)$ & $0.29(0.18-0.48)$ \\
\hline
\end{tabular}

Note:-Percentages are shown with 95\% confidence intervals in parentheses; LR indicates likelihood ratio.

\section{A: Sensitivity TOF-MRA}

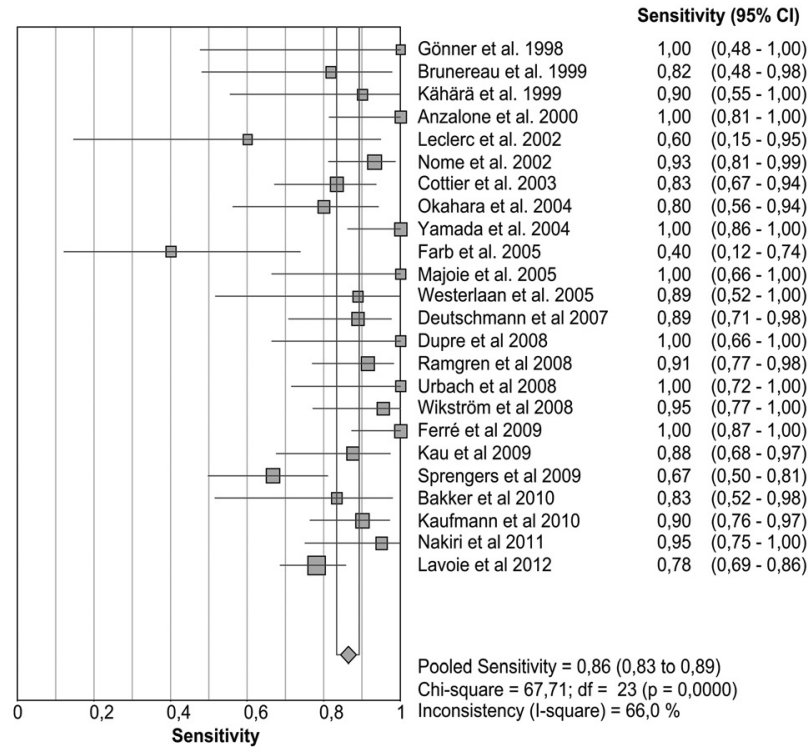

\section{C: Sensitivity CE-MRA}

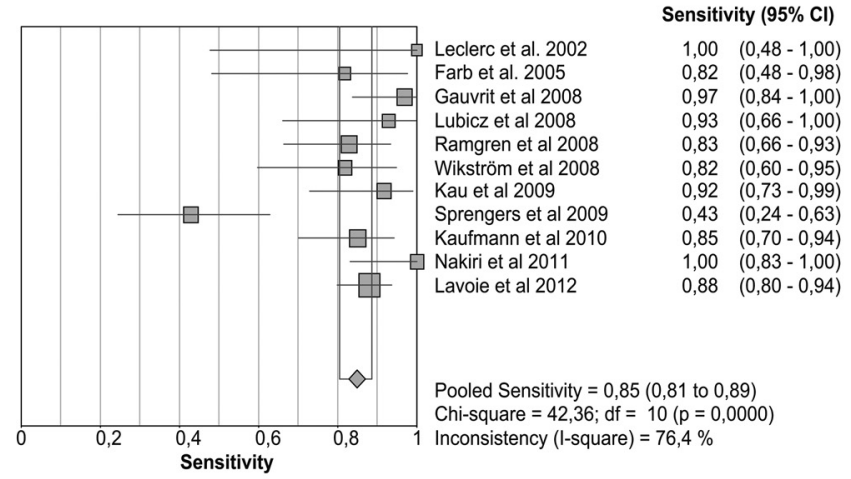

\section{B: Specificity TOF-MRA}

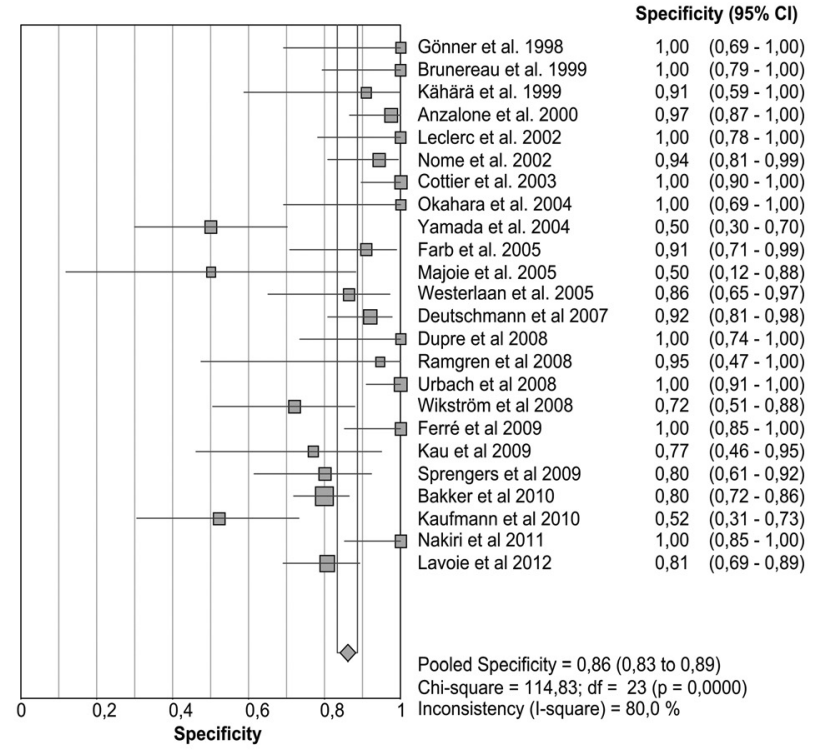

D: Specificity CE-MRA

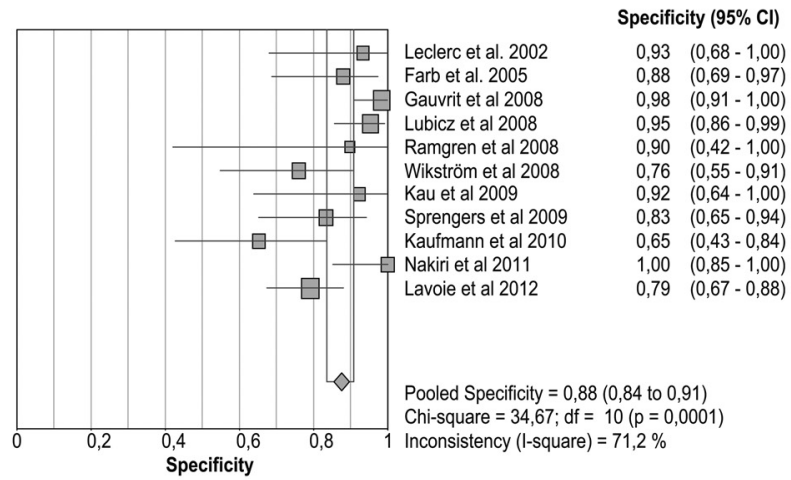

FIG 2. Pooled sensitivity/specificity in detecting any recurrent flow. A, Sensitivity for TOF-MRA. B, Specificity for TOF-MRA. C, Sensitivity for CE-MRA. D, Specificity for CE-MRA.

Twelve studies assessed both TOF-MRA and CE-MRA for the detection of recanalization in coiled intracranial aneurysms in the same subjects. ${ }^{29,32,36,40,42,60,62,66,68,70,74,75}$

\section{Study Quality Assessment}

We analyzed the methodologic quality of the 26 articles included in our review according to the GRADE criteria (On-line Table 3). ${ }^{12-22}$ There was disagreement between the assessments by the 2 researchers with respect to 5 of 104 GRADE scores, resulting in a Cohen $\kappa$ of 0.81 . All of the articles comprised valid studies comparing MRA with the reference standard (DSA). Because of this validity, all of the studies started with a maximal quality score of $4{ }^{12}$ None of the articles gave any indication that they contained serious inconsistencies or were imprecise. ${ }^{12-22}$ Two studies were rated down because of indirectness; they did not provide enough information concerning their MRA techniques or only included anterior communicating artery aneurysms. ${ }^{28,32}$ Quality was rated down in 14 studies because of the following major limitations: the studies did not include consecutive patients, the studies were not prospective, or there was no blinding of the researchers. ${ }^{26,29,33,36,38-40,43,55,59,60,62,68,70}$

\section{Data Analysis}

The pooled results for the sensitivity and specificity of TOF-MRA and CE-MRA are presented in Table 1 . The sensitivity and specificity for the detection of any recanalization, meaning residual 


\section{A: SROC TOF-MRA}

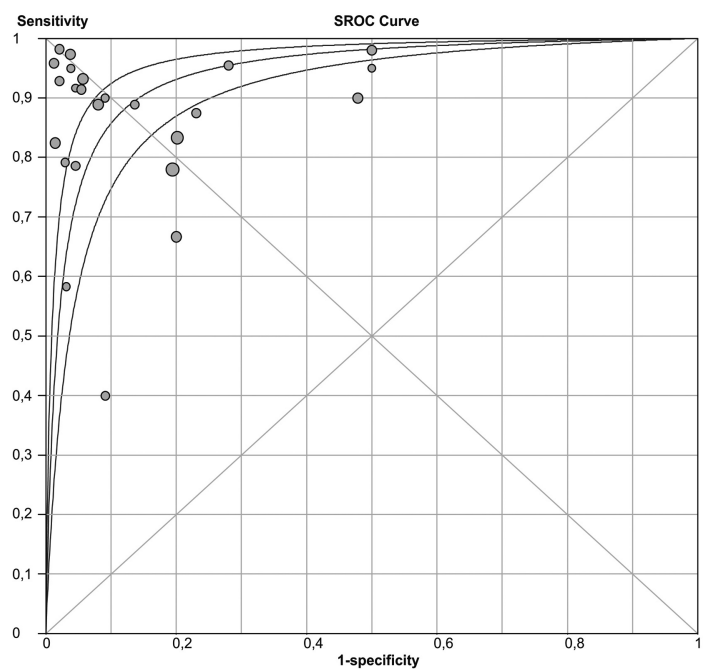

\section{B: SROC CE-MRA}

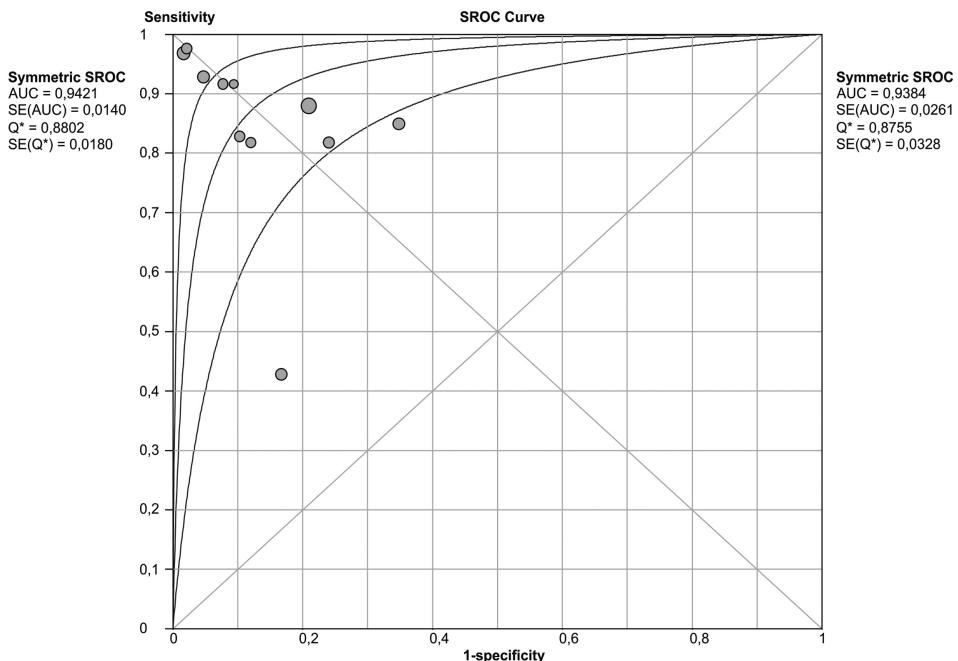

FIG 3. $A$, Summary receiver operating characteristic for TOF-MRA. B, Summary receiver operating characteristic for CE-MRA.

Table 2: Subclasses of sensitivity and specificity in TOF-MRA and CE-MRA

\begin{tabular}{|c|c|c|c|c|}
\hline & \multicolumn{2}{|c|}{ TOF-MRA } & \multicolumn{2}{|c|}{ CE-MRA } \\
\hline & Sensitivity $(95 \% \mathrm{CI})$ & Specificity $(95 \% \mathrm{CI})$ & Sensitivity $(95 \% \mathrm{CI})$ & Specificity $(95 \% \mathrm{Cl})$ \\
\hline Retrospective & $90 \%(85-94 \%)$ & $87 \%(82-91 \%)$ & $93 \%(85-97 \%)$ & $95 \%(90-98 \%)$ \\
\hline Prospective & $85 \%(81-88 \%)$ & $86 \%(82-89 \%)$ & $82 \%(77-87 \%)$ & $82 \%(75-87 \%)$ \\
\hline 2D DSA & $85 \%(82-89 \%)$ & $91 \%(88-93 \%)$ & $80 \%(74-85 \%)$ & $82 \%(76-88 \%)$ \\
\hline 3D DSA & $90 \%(84-95 \%)$ & $76 \%(70-82 \%)$ & $92 \%(86-96 \%)$ & $93 \%(88-96 \%)$ \\
\hline $1-1.5 \mathrm{~T}$ & $86 \%(83-89 \%)$ & $85 \%(81-88 \%)$ & $89 \%(84-92 \%)$ & $87 \%(83-91 \%)$ \\
\hline 3T & $88 \%(82-92 \%)$ & $87 \%(80-92 \%)$ & $79 \%(71-86 \%)$ & $83 \%(74-91 \%)$ \\
\hline GRADE 2-3 & $87 \%(82-90 \%)$ & $86 \%(81-89 \%)$ & $77 \%(70-84 \%)$ & $85 \%(79-90 \%)$ \\
\hline GRADE 4 & $86 \%(81-90 \%)$ & $87 \%(83-90 \%)$ & $92 \%(86-95 \%)$ & $90 \%(85-94 \%)$ \\
\hline Weighted results & $86 \%(85-88 \%)$ & $86 \%(85-88 \%)$ & $87 \%(85-89 \%)$ & $88 \%(86-90 \%)$ \\
\hline
\end{tabular}

Percentages are shown with $95 \%$ confidence intervals in parentheses.

neck or residual aneurysm, are shown in Fig $2 A-D$. TOF-MRA had both a pooled sensitivity and specificity of $86 \%$ (95\% CI: 83-89\%). Pooled sensitivity and specificity of CE-MRA were $85 \%$ (95\% CI: $81-89 \%$ ) and 88\% (95\% CI: $84-91 \%$ ), respectively. SROC curves are displayed in Fig $3 A,-B$ for TOF-MRA and CEMRA. As shown in Fig $2 A-D$, the results were subject to heterogeneity, with $I^{2}$ values ranging between $66-80 \%$. For subanalysis, different study variables were distinguished: retrospective versus prospective studies, 2D versus 3D DSA, different MR field strengths, GRADE criteria, and weighted results according to GRADE (Table 2).

\section{DISCUSSION}

The results of our meta-analysis reveal that MRA now has a high degree of sensitivity and specificity in detecting any recanalization during the follow-up of coiled intracranial aneurysms. However, a subanalysis for residual neck or residual aneurysm (Raymond scale 2 or 3 , respectively) revealed lower sensitivity and specificity of both MRA techniques compared with DSA as the reference standard (Table 1). A possible explanation is the small number of studies and patients included therein, which is reflected in the large 95\% confidence intervals. Another potential explanation is false-positive findings seen on DSA possibly caused by pulsation artifacts. ${ }^{48}$ However, this comparison makes MRA the reference standard compared with DSA. Because our study compared MRA with the reference standard, DSA, these cases also were judged in favor of DSA. This results in false-negative values for the MRA and a lower sensitivity.

This subanalysis also showed lower sensitivities of the CEMRA compared with the TOF-MRA for the detection of residual neck or residual aneurysm. The contrast timing together with the narrow interval of scanning in CE-MRA might be the cause of this lower sensitivity. The short time window between the arterial and venous phase of contrast enhancement to avoid venous enhancement and vessel overlap lowers the spatial resolution. ${ }^{60}$ Additionally, the acquisition time for TOF-MRA is much longer compared with CE images, leading to improved resolution. The disadvantage of TOF-MRA is its limited coverage; however, TOF is adequate for the evaluation of intracranial vessels. Suboptimal imaging in CE-MRA may therefore lead to more false-negative values, especially in small remnants, lowering the sensitivity.

Significant sources of heterogeneity in this meta-analysis are variations in study design and reporting of data. Evaluation of the studies revealed 5 possible explanations for this heterogeneity: 1) Publication bias remains a potential cause of heterogeneity, because articles with better results are more likely to be published than studies with insignificant or negative findings. 2) Not all of the studies had a prospective design and enrolled patients consec- 
utively, which can be a cause of bias. ${ }^{76}$ Sixteen of the 26 were prospective $27,28,32,36,38,42,55,60-62,64,68-70,74,75$; only 12 studies included consecutive patients. ${ }^{28,32,42,48,56,60,61,64,66,69,74,75}$ Retrospective studies tended to be better, with low heterogeneity, compared with the results of the prospective studies, though these findings were not statistically significant (Table 2). 3) For the reference standard, 8 reference studies used 3D (rotational) DSA for comparison to MRA, ${ }^{38,39,56,59,66,69,70,74}$ whereas the other studies used 2D DSA. Because 3D DSA is better at evaluating recurrent flow in intracranial aneurysms, ${ }^{77,78}$ the use of the $2 \mathrm{D}$ DSA may reduce calculated specificity but also increase calculated sensitivity of MRA if a true recanalization is missed by DSA. The use of DSA as the reference standard will potentially cause DSA false-negative values to count as MRA false-positive values. In general, MRA tends to perform better when compared with 3D DSA than when compared with 2D DSA (Table 2). 4) Heterogeneity may also be caused by different field strengths used in the various studies. ${ }^{79,80}$ Five studies only researched 3T MRA, ${ }^{42,61,64,68,74}$ whereas 2 articles studied both 3T and 1.5T MRA techniques. ${ }^{60,70}$ Two studies were performed with a $1 \mathrm{~T}$ scanner. ${ }^{27,33}$ The rest of the articles evaluated MRA by use of $1.5 \mathrm{~T}$ units. There is a trend toward higher pooled sensitivity and specificity of TOF-MRA with 3T units compared with $1.5 \mathrm{~T}$ scanners, though the 95\% confidence intervals overlap (Table 2 ). This trend might be caused by the higher resolution of images created with a 3T MR imaging compared with $1.5 \mathrm{~T}$ scanners. ${ }^{81}$ However, the sensitivity and specificity of 3T CE-MRA is lower than that at $1.5 \mathrm{~T}$, though this difference is not statistically significant. Again, the small number of studies researching CE-MRA at 3T limits the interpretation of results and might be the cause of this nonsignificant difference without reflecting any underlying inferiority. ${ }^{42,60,68,70,74} 5$ ) A final cause of heterogeneity might be the difference in study quality as judged by the GRADE criteria. ${ }^{12-22}$ GRADE 4 quality studies tend to have higher sensitivity and specificity. This difference reaches significance in sensitivity for CEMRA (Table 2). Weighted by GRADE, overall comparisons between TOF-MRA and CE-MRA revealed results that were similar to the overall pooled results.

Our results provide a more detailed and updated evaluation of the accuracy of MRA for follow-up of coiled intracranial aneurysms than earlier work by Kwee and Kwee ${ }^{8}$ Our detailed subanalysis of results reveals consistently good performance of MRA techniques with pooled sensitivities and specificities well above $80 \%$. For the important question of residual aneurysms (Raymond grade 4), CE-MRA even provides a pooled sensitivity and specificity $>90 \%$, with a lower $95 \%$ confidence interval of $\geq 85 \%$.

\section{CONCLUSIONS}

This meta-analysis has revealed that MRA has a high diagnostic performance when it comes to the detection of residual flow in the follow-up of intracranial aneurysms treated with endovascular coil occlusion and therefore should be routinely used for follow-up. CE-MRA did not perform significantly better than TOF-MRA, indicating that follow-up with the latter should be adequate.

\section{ACKNOWLEDGMENTS}

We would like to thank A.H.J. Tillema for support with our literature search.

Disclosures: Joost de Vries-UNRELATED: Consultancy: Stryker Neurovascular (consultancy and proctoring); Stock/Stock Options: Stock options in relation to SurpassStryker Neurovascular; Other: Compensation for training courses for Stryker Neurovascular held at the campus of the Radboud UMC Nijmegen, Netherlands. * Ronald Bartels_UNRELATED: Board Membership: Secretary of CSRS-es, Comments: Only traveling costs and hotel costs for board meetings are reimbursed ( ${ }^{*}$ money paid to institution)

\section{REFERENCES}

1. Rinkel GJ, Djibuti M, Algra A, et al. Prevalence and risk of rupture of intracranial aneurysms: a systematic review. Stroke 1998;29:251-56

2. Vlak MH, Algra A, Brandenburg R, et al. Prevalence of unruptured intracranial aneurysms, with emphasis on sex, age, comorbidity, country, and time period: a systematic review and meta-analysis. Lancet Neurol 2011;10:626-36

3. Molyneux A, Kerr R, Stratton I, et al. International Subarachnoid Aneurysm Trial (ISAT) of neurosurgical clipping versus endovascular coiling in 2143 patients with ruptured intracranial aneurysms: a randomised trial. Lancet 2002;360:1267-74

4. Naggara ON, White PM, Guilbert F, et al. Endovascular treatment of intracranial unruptured aneurysms: systematic review and metaanalysis of the literature on safety and efficacy. Radiology 2010;256:887-97

5. Dawkins AA, Evans AL, Wattam J, et al. Complications of cerebral angiography: a prospective analysis of 2,924 consecutive procedures. Neuroradiology 2007;49:753-59

6. Thiex R, Norbash AM, Frerichs KU. The safety of dedicated-team catheter-based diagnostic cerebral angiography in the era of advanced noninvasive imaging. AJNR Am J Neuroradiol 2010;31: $230-34$

7. Willinsky RA, Taylor SM, TerBrugge K, et al. Neurologic complications of cerebral angiography: prospective analysis of 2,899 procedures and review of the literature. Radiology 2003;227:522-28

8. Kwee TC, Kwee RM. MR angiography in the follow-up of intracranial aneurysms treated with Guglielmi detachable coils: systematic review and meta-analysis. Neuroradiology 2007;49:703-13

9. Raymond J, Guilbert F, Weill A, et al. Long-term angiographic recurrences after selective endovascular treatment of aneurysms with detachable coils. Stroke 2003;34:1398-403

10. Roy D, Raymond J, Bouthillier A, et al. Endovascular treatment of ophthalmic segment aneurysms with Guglielmi detachable coils. AJNR Am J Neuroradiol 1997;18:1207-15

11. Roy D, Milot G, Raymond J. Endovascular treatment of unruptured aneurysms. Stroke 2001;32:1998-2004

12. Schunemann HJ, Oxman AD, Brozek J, et al. Grading quality of evidence and strength of recommendations for diagnostic tests and strategies. BMJ 2008;336:1106-10

13. Guyatt GH, Oxman AD, Schunemann HJ, et al. GRADE guidelines: a new series of articles in the Journal of Clinical Epidemiology. J Clin Epidemiol 2011;64:380-82

14. Guyatt G, Oxman AD, Akl EA, et al. GRADE guidelines, 1: introduction: GRADE evidence profiles and summary of findings tables. J Clin Epidemiol 2011;64:383-94

15. Guyatt GH, Oxman AD, Kunz R, et al. GRADE guidelines, 2: framing the question and deciding on important outcomes. J Clin Epidemiol 2011;64:395-400

16. Balshem H, Helfand $M$, Schunemann HJ, et al. GRADE guidelines, 3: rating the quality of evidence. J Clin Epidemiol 2011;64:401-06

17. Guyatt GH, Oxman AD, Vist G, et al. GRADE guidelines, 4: rating the quality of evidence: study limitations (risk of bias). J Clin Epidemiol 2011;64:407-15

18. Guyatt GH, Oxman AD, Montori V, et al. GRADE guidelines, 5: rating the quality of evidence: publication bias. J Clin Epidemiol 2011;64:1277-82 
19. Guyatt GH, Oxman AD, Kunz R, et al. GRADE guidelines, 6: rating the quality of evidence: imprecision. J Clin Epidemiol 2011;64: 1283-93

20. Guyatt $\mathrm{GH}$, Oxman $\mathrm{AD}, \mathrm{Kunz}$ R, et al. GRADE guidelines, 7: rating the quality of evidence: inconsistency. J Clin Epidemiol 2011;64: $1294-302$

21. Guyatt $\mathrm{GH}$, Oxman $\mathrm{AD}, \mathrm{Kunz} \mathrm{R}$, et al. GRADE guidelines, 8: rating the quality of evidence: indirectness. J Clin Epidemiol 2011;64: 1303-10

22. Guyatt GH, Oxman AD, Sultan S, et al. GRADE guidelines, 9: rating up the quality of evidence. J Clin Epidemiol 2011;64:1311-16

23. Brennan P, Silman A. Statistical methods for assessing observer variability in clinical measures. BMJ 1992;304:1491-94

24. Zamora J, Abraira V, Muriel A, et al. Meta-DiSc: a software for metaanalysis of test accuracy data. BMC Med Res Methodol 2006;6:31

25. Derdeyn CP, Graves VB, Turski PA, et al. MR angiography of saccular aneurysms after treatment with Guglielmi detachable coils: preliminary experience. AJNR Am J Neuroradiol 1997;18:279-86

26. Gonner F, Heid O, Remonda L, et al. MR angiography with ultrashort echo time in cerebral aneurysms treated with Guglielmi detachable coils. AJNR Am J Neuroradiol 1998;19:1324-28

27. Brunereau L, Cottier JP, Sonier CB, et al. Prospective evaluation of time-of-flight MR angiography in the follow-up of intracranial saccular aneurysms treated with Guglielmi detachable coils. J Comput Assist Tomogr 1999;23:216-23

28. Kahara VJ, Seppanen SK, Ryymin PS, et al. MR angiography with three-dimensional time-of-flight and targeted maximum-intensity-projection reconstructions in the follow-up of intracranial aneurysms embolized with Guglielmi detachable coils. AJNR Am J Neuroradiol 1999;20:1470-75

29. Anzalone N, Righi C, Simionato F, et al. Three-dimensional time-offlight MR angiography in the evaluation of intracranial aneurysms treated with Guglielmi detachable coils. AJNR Am J Neuroradiol 2000;21:746-52

30. Boulin A, Pierot L. Follow-up of intracranial aneurysms treated with detachable coils: comparison of gadolinium-enhanced $3 \mathrm{D}$ time-of-flight MR angiography and digital subtraction angiography. Radiology 2001;219:108-13

31. Weber W, Yousry TA, Felber SR, et al. Noninvasive follow-up of GDC-treated saccular aneurysms by MR angiography. Eur Radiol 2001;11:1792-97

32. Leclerc X, Navez JF, Gauvrit JY, et al. Aneurysms of the anterior communicating artery treated with Guglielmi detachable coils: follow-up with contrast-enhanced MR angiography. AJNR Am J Neuroradiol 2002;23:1121-27

33. Nome T, Bakke SJ, Nakstad PH. MR angiography in the follow-up of coiled cerebral aneurysms after treatment with Guglielmi detachable coils. Acta Radiol 2002;43:10-14

34. Park SW, Han MH, Cha SH, et al. PC-based 3D reconstruction of MR angiography in evaluation of intracranial aneurysms. The value of pre-treatment planning for embolization and post-treatment follow-up. Interv Neuroradiol 2002;8:169-81

35. Cottier JP, Bleuzen-Couthon A, Gallas S, et al. Follow-up of intracranial aneurysms treated with detachable coils: comparison of plain radiographs, 3D time-of-flight MRA and digital subtraction angiography. Neuroradiology 2003;45:818-24

36. Cottier JP, Bleuzen-Couthon A, Gallas S, et al. Intracranial aneurysms treated with Guglielmi detachable coils: is contrast material necessary in the follow-up with 3D time-of-flight MR angiography? AJNR Am J Neuroradiol 2003;24:1797-803

37. Zizka J, Krajina A, Lojik M. The reliability of MR angiography as the sole imaging method for non-invasive follow-up of intracranial aneurysms treated with Guglielmi detachable coils. Rivista di Neuroradiologia 2003;16:1137-38

38. Okahara M, Kiyosue H, Hori Y, et al. Three-dimensional time-offlight MR angiography for evaluation of intracranial aneurysms after endosaccular packing with Guglielmi detachable coils: compar- ison with 3D digital subtraction angiography. Eur Radiol 2004; 14:1162-68

39. Yamada N, Hayashi K, Murao K, et al. Time-of-flight MR angiography targeted to coiled intracranial aneurysms is more sensitive to residual flow than is digital subtraction angiography. AJNR Am J Neuroradiol 2004;25:1154-57

40. Farb RI, Nag S, Scott JN, et al. Surveillance of intracranial aneurysms treated with detachable coils: a comparison of MRA techniques. Neuroradiology 2005;47:507-15

41. Gauvrit JY, Leclerc X, Pernodet M, et al. Intracranial aneurysms treated with Guglielmi detachable coils: usefulness of 6-month imaging follow-up with contrast-enhanced MR angiography. AJNR Am J Neuroradiol 2005;26:515-21

42. Majoie CBLM, Sprengers ME, Van Rooij WJJ, et al. MR angiography at $3 \mathrm{~T}$ versus digital subtraction angiography in the follow-up of intracranial aneurysms treated with detachable coils. AJNR Am J Neuroradiol 2005;26:1349-56

43. Westerlaan HE, van der Vliet AM, Hew JM, et al. Time-of-flight magnetic resonance angiography in the follow-up of intracranial aneurysms treated with Guglielmi detachable coils. Neuroradiology 2005;47:622-29

44. Gauvrit JY, Leclerc X, Caron S, et al. Intracranial aneurysms treated with Guglielmi detachable coils: imaging follow-up with contrastenhanced MR angiography. Stroke 2006;37:1033-37

45. Pierot L, Delcourt C, Bouquigny F, et al. Follow-up of intracranial aneurysms selectively treated with coils: prospective evaluation of contrast-enhanced MR angiography. AJNR Am J Neuroradiol 2006;27:744-49

46. Saguchi T, Murayama Y, Ishibashi T, et al. Efficacy of 3-D reconstructed time of flight MRA follow-up of the embolized cerebral aneurysms. Intervent Neuroradiol 2006;12(Suppl 1):45-48

47. de Gast AN, Sprengers ME, van Rooij WJ, et al. Long-term 3T MR angiography follow-up after therapeutic occlusion of the internal carotid artery to detect possible de novo aneurysm formation. AJNR Am J Neuroradiol 2007;28:508-10

48. Deutschmann HA, Augustin M, Simbrunner J, et al. Diagnostic accuracy of 3D time-of-flight MR angiography compared with digital subtraction angiography for follow-up of coiled intracranial aneurysms: influence of aneurysm size. AJNR Am J Neuroradiol 2007;28:628-34

49. Lubicz B, Levivier M, Sadeghi N, et al. Immediate intracranial aneurysm occlusion after embolization with detachable coils: a comparison between MR angiography and intra-arterial digital subtraction angiography. J Neuroradiol 2007;34:190-97

50. Poncyljusz W, Czechowski J, Corr P, et al. MR-angiography as a method for evaluating endovascular coiled cerebral aneurysms. Med Sci Monit 2007;13(Suppl 1):59-64

51. Wallace RC, Karis JP, Partovi S, et al. Noninvasive imaging of treated cerebral aneurysms, part I: MR angiographic follow-up of coiled aneurysms. AJNR Am J Neuroradiol 2007;28:1001-08

52. Wong JH, Mitha AP, Willson M, et al. Assessment of brain aneurysms by using high-resolution magnetic resonance angiography after endovascular coil delivery. J Neurosurg 2007;107:283-89

53. Agid R, Willinsky RA, Lee SK, et al. Characterization of aneurysm remnants after endovascular treatment: contrast-enhanced MR angiography versus catheter digital subtraction angiography. AJNR Am J Neuroradiol 2008;29:1570-74

54. Buhk JH, Kallenberg K, Mohr A, et al. No advantage of time-of-flight magnetic resonance angiography at 3 Tesla compared to 1.5 Tesla in the follow-up after endovascular treatment of cerebral aneurysms. Neuroradiology 2008;50:855-61

55. Dupre S, Coulthard A. Follow up of coiled intracranial aneurysms with standard resolution and higher resolution magnetic resonance angiography. J Med Imaging Radiat Oncol 2008;52:57-63

56. Gauvrit JY, Caron S, Taschner CA, et al. Intracranial aneurysms treated with Guglielmi detachable coils: long-term imaging follow-up with contrast-enhanced magnetic resonance angiography. J Neurosurg 2008;108:443-49 
57. Hiratsuka Y, Miki H, Kiriyama I, et al. Diagnosis of unruptured intracranial aneurysms: 3T MR angiography versus 64-channel multi-detector row CT angiography. Magn Reson Med Sci 2008; 7:169-78

58. Khan R, Wallace RC, Fiorella DJ. Magnetic resonance angiographic imaging follow-up of treated intracranial aneurysms. Top Magn Reson Imaging 2008;19:231-39

59. Lubicz B, Neugroschl C, Collignon L, et al. Is digital substraction angiography still needed for the follow-up of intracranial aneurysms treated by embolisation with detachable coils? Neuroradiology 2008;50:841-48

60. Ramgren B, Siemund R, Cronqvist M, et al. Follow-up of intracranial aneurysms treated with detachable coils: comparison of 3D inflow MRA at $3 \mathrm{~T}$ and $1.5 \mathrm{~T}$ and contrast-enhanced MRA at $3 \mathrm{~T}$ with DSA. Neuroradiology 2008;50:947-54

61. Urbach H, Dorenbeck U, Von Falkenhausen M, et al. Three-dimensional time-of-flight MR angiography at $3 \mathrm{~T}$ compared to digital subtraction angiography in the follow-up of ruptured and coiled intracranial aneurysms: a prospective study. Neuroradiology 2008;50:383-89

62. Wikstrom J, Ronne-Engstrom E, Gal G, et al. Three-dimensional time-of-flight (3D TOF) magnetic resonance angiography (MRA) and contrast-enhanced MRA of intracranial aneurysms treated with platinum coils. Acta Radiol 2008;49:190-96

63. Buhk JH, Kallenberg K, Mohr A, et al. Evaluation of angiographic computed tomography in the follow-up after endovascular treatment of cerebral aneurysms: a comparative study with DSA and TOF-MRA. Eur Radiol 2009;19:430-36

64. Ferre JC, Carsin-Nicol B, Morandi X, et al. Time-of-flight MR angiography at $3 \mathrm{~T}$ versus digital subtraction angiography in the imaging follow-up of 51 intracranial aneurysms treated with coils. Eur J Radiol 2009;72:365-69

65. Gallas S, Januel AC, Pasco A, et al. Long-term follow-up of $\mathbf{1 0 3 6}$ cerebral aneurysms treated by bare coils: a multicentric cohort treated between 1998 and 2003. AJNR Am J Neuroradiol 2009; 30:1986-92

66. Kau T, Gasser J, Celedin S, et al. MR angiographic follow-up of intracranial aneurysms treated with detachable coils: evaluation of a blood-pool contrast medium. AJNR Am J Neuroradiol 2009;30: 1524-30

67. Monninghoff C, Maderwald S, Theysohn JM, et al. Evaluation of intracranial aneurysms with $7 \mathrm{~T}$ versus $1.5 \mathrm{~T}$ time-of-flight $\mathrm{MR}$ angiography: initial experience. Rofo 2009;181:16-23

68. Sprengers ME, Schaafsma JD, van Rooij WJ, et al. Evaluation of the occlusion status of coiled intracranial aneurysms with MR angiog- raphy at 3T: is contrast enhancement necessary? AJNR Am J Neuroradiol 2009;30:1665-71

69. Bakker NA, Westerlaan HE, Metzemaekers JD, et al. Feasibility of magnetic resonance angiography (MRA) follow-up as the primary imaging modality after coiling of intracranial aneurysms. Acta Radiol 2010;51:226-32

70. Kaufmann TJ, Huston IJ, Cloft HJ, et al. A prospective trial of $3 \mathrm{~T}$ and 1.5T time-of-flight and contrast-enhanced $M R$ angiography in the follow-up of coiled intracranial aneurysms. AJNR Am J Neuroradiol 2010;31:912-18

71. Schaafsma JD, Velthuis BK, Majoie CB, et al. Intracranial aneurysms treated with coil placement: test characteristics of follow-up MR angiography: multicenter study. Radiology 2010;256:209-18

72. Shankar JJS, Lum C, Parikh N, et al. Long-term prospective follow-up of intracranial aneurysms treated with endovascular coiling using contrast-enhanced MR angiography. AJNR Am J Neuroradiol 2010;31:1211-15

73. Tailor J, Goetz P, Chandrashekar H, et al. Stability of ruptured intracranial aneurysms treated with detachable coils: is delayed follow-up angiography warranted? Br J Neurosurg 2010;24:405-09

74. Nakiri GS, Santos AC, Abud TG, et al. A comparison between magnetic resonance angiography at 3 Teslas (time-of-flight and contrast enhanced) and flat-panel digital subtraction angiography in the assessment of embolized brain aneurysms. Clinics 2011;66: 641-48

75. Lavoie P, Gariepy JL, Milot G, et al. Residual flow after cerebral aneurysm coil occlusion: diagnostic accuracy of MR angiography. Stroke 2012;43:740-46

76. Berbano EP, Baxi N. Impact of patient selection in various study designs: identifying potential bias in clinical results. South Med J 2012;105:149-55

77. Sugahara T, Korogi Y, Nakashima K, et al. Comparison of 2D and 3D digital subtraction angiography in evaluation of intracranial aneurysms. AJNR Am J Neuroradiol 2002;23:1545-52

78. Shi WY, Li YD, Li MH, et al. 3D rotational angiography with volume rendering: the utility in the detection of intracranial aneurysms. Neurol India 2010;58:908-13

79. Bernstein MA, Huston J 3rd, Lin C, et al. High-resolution intracranial and cervical MRA at 3.0T: technical considerations and initial experience. Magn Reson Med 2001;46:955-62

80. Al-Kwifi O, Emery DJ, Wilman AH. Vessel contrast at three Tesla in time-of-flight magnetic resonance angiography of the intracranial and carotid arteries. Magn Reson Imaging 2002;20:181-87

81. Willinek WA, Born M, Simon B, et al. Time-of-flight MR angiography: comparison of 3.0-T imaging and 1.5-T imaginginitial experience. Radiology 2003;229:913-20 